\title{
Cutting out the middleman
}

\author{
Innovation in translational research has often emerged from the biotechnology industry. In a climate in which it is \\ increasingly hard to found a successful company, direct technology transfer from academia to the pharmaceutical \\ industry poses an additional threat to small biotechs.
}

$\mathbf{T}^{\circ}$ say that the biotechnology industry is in dire straits has become a bit of a cliché, and in these pages we have discussed some of the challenges it faces: insufficient financial resources, lack of qualified personnel to navigate the translational labyrinth and a surplus of half-validated ideas that provide the scientific basis for many start-up companies.

It's ironic to find the biotech industry in such an uncomfortable position if we consider how frequently small companies feed the pipeline of the pharmaceutical industry. If we look at the targets that a given pharma company focuses on and estimate how many of them were discovered and validated by its own researchers, we find a wide variety of figures, ranging from $5 \%$ to $50 \%$, depending on the therapeutic area and on how much the company fosters innovation. The remainder of its targets comes mostly from licenses and partnerships with academic institutions or small companies.

Even though these figures should make us feel positive about the strength of the biotech industry, its prospects are not likely to improve in the short run. Venture capital, for example, has never had much patience and scoffs more than ever at the idea of waiting for longer than a couple of years to see a return on an investment. So, venture funds have migrated to the greener pastures of information technology and green energy, fields in which investors perceive their gambles to be smaller than in biomedicine.

There is also a geographical problem when it comes to money. Venture capital firms much prefer to do business locally, and they happen to be concentrated in just a handful of places. In the US, for example, over $60 \%$ of venture funds are concentrated in northern and southern California, Boston and New York City. In Europe, only England, Germany and Switzerland have enough venture capital to appear in a global investment map. Thus, researchers from other regions have to either compete for a much smaller pool of local funds or make extreme concessions to gain access to the wealth of the rich areas.

These two factors-geography and competition from other disciplines - plus the two that we highlighted last month-unrealistic expectations about the value of a patent and an increasing need for a thorough validation of a target before funds become available- have pushed the biotech industry to its current predicament. How the industry comes out of it is uncertain, but several scenarios come to mind.

In a particularly optimistic one (to the point of delusion), cash will start flowing again once the global economy recovers from its current meltdown. Fortunately, not many researchers-turned-entrepreneurs hold on to this romantic idea.
In a second, darwinian scenario, biotech firms will only thrive in regions with the right mix of rigorous and original science, a strong community of investors and people with the appropriate expertiselegal, commercial and scientific - to set up a viable company. In such a world, the biotech global map will be even more distorted than it currently is, with no more than five cities worldwide able to carry a vibrant biotech community.

In a third, cataclysmic scenario, investing in a biotech company will be regarded as obsolete, leading to the extinction of the sector. In the absence of an intermediary in the form of a start-up company, 'big pharma' will partner directly with academics. In fact, partnerships between academic institutions and the pharmaceutical industry are becoming increasingly common, and it's not difficult to see how these ties can become more and more necessary to academics in the absence of alternatives to generate income from patents.

In such a world, the pharma industry will have the strongest hand to call the shots. After all, once you cut the middleman from the deal, the price of a product naturally goes down. So, big pharma will expect to pay much less for a not-fully fledged target or technology. And, facing a vast market of competing intellectual property, companies will be in the enviable position to pick and choose, dictating the terms on which they want to do business.

If this scenario comes to pass, academic institutions with entrepreneurial aspirations must overcome their natural aversion to interacting in this way with a commercial partner, learning instead to maximize the value and translational appeal of the science they produce. It goes without saying that the impact of this scenario on academic science would be profound.

At the same time, pharma companies must appreciate that not everything in this scenario is favorable for their interests. If the number of biotech companies drastically declines, big pharma won't be able to take advantage of potential deals with a partner that can advance a project down the translational highway much more than an academic lab. For pharma companies, a paucity of biotech firms will mean that they will either have to take more risks themselves or keep smaller product pipelines.

Last, if pharma is to truly take advantage of this potential scenario, they must not see their academic counterparts as mere providers of cheap intellectual property, but rather as true partners with the same goal of delivering new therapies. Only those companies that truly invest in these relationships will have a competitive advantage in what is an increasingly tough environment. 